\title{
Suscetibilidade de Biomphalaria occidentalis do Acre e Mato Grosso à infecção pelo Schistosoma mansoni e sua implicação na epidemiologia da esquistosomose na Amazônia Ocidental, Brasil(1)
}

\author{
Carlos E. A. Coimbra Jr. ( $\left.{ }^{2}\right)$ \\ Luís A. Engel $\left({ }^{3}\right)$
}

\begin{abstract}
Resumo
É testada a suscetibilidade da Biomphalaria occidentalis de Sena Madureira (Acre) e Cuiabá (Mato Grosso) à infecção pelas cepas de Schistosoma man soni de São José dos Campos (São Paulo) e Paulista (Pernambuco), com resultado negativo. Săo tecidas consideraçōes sobre os focos de esquistossomose des. critos na região Amazônica e discute-se o potencial de transmissão de $\mathbf{S}$. mansoni por $\mathbf{B}$. occidentalis na Ama zônia Ocidental.
\end{abstract}

\section{INTRODUÇão}

A ocorrência da esquistossomose no Brasil está historicamente ligada aos movimentos migratórios humanos e à expansão das fron. teiras agrícolas. Em virtude da larga dispersão de moluscos do gênero Biomphalaria, podemos admitir que todas as regiões do país estão pctencialmente ameaçadas, a continuarem impe. rando as mesmas condições sociais e sanitárias em que vive grande parte da população: brasıieira. Paradoxalmente, são as regiões onde grandes investimentos têm sido realizá. dos, com a abertura de estradas, construção de barragens, itrigação e coionização, as mais expostas à infecção (CNPq, 1978) .

Lesde a descoberta do primeiro foco da doença na Amazônia, registrado por Machado \& Martins (1951) em Fordlândia, no Estado do Pará, e considerado pelos autores como um foco recente, cuja origem estaria provavelmente em migrantes nordestinos que foram para a região na época da II Guerra, na Categoria de "soldados da borracha", outros focos vêm sendo encontrados. Mello \& Gueiros (1959) descreveram o foco de Quatipuru, também ne
Pará, e Galvão (1968), relata a transmissão da doença em Belém.

Ouanto à ocorrência de moluscos do gênero Biomphalaria na Amazônia, destaca-se a espécie $B$. straminea, associada aos primeiros focos descritos na região e de ampla distribuição em toda a Bacia, como revelam os trabathos de Sioli (1953), que a coletou em três localidades no Estado do Amazonas e em quatorze no Pará. Fraiha \& Moraes (1976) mencionam o achado de $B$. straminea em Altamira e Santarém, no Pará. Barbosa (1968) não obteve intecção de $B$. straminea proveniente de Manaus, com a cepa pernambucana de $S$. mansoni. No entanto, Ruiz (1974/75), utilizando exemplares coletados na região da rodovia Transamazônica, conseguiu infectá-los, mas o autor nảo diz em seu trabalho qual a cepa de S. mansoni utilizada.

A presença de $B$. glabrata é constatada nos arreciores de Quatipuru, Pará (Fraiha, 1977), tendo sido encontrados exemplares naturalmente infectados por $S$. mansoni.

A espécie B. amazônica, descrita por Paraense (1966), foi pela primeira vez observada em Manaus e na ilha do Careiro, e, com base em estudos laboratoriais (Corrêa \& Paraense, 1971), é tida como um transmissor em poten. cial da doença em sua área de distribuição. Aincia referente a essa espécie, Paraense Apud Fraiha \& Moraes, 1979), menciona sua ocorrência em Porto Velho, Estado de Rondô. nia.

Em relação a $B$. tenagophila, havia sido ob. servada esporadicamente na região até que, com a descrição de $B$. occidentalis por Paraen.

(1) - Prabalho realizado com auxílio do CNPq.

( 2 ) - Bolsista do CNPq. Núcleo de Medicina Tropical - Universidade de Brasília, DF.

(3) - Acadêmico de Ciências Biológicas - Universidade de Brasília, DF. 
se (1981), podemos considerar as menções anteriores de B. tenagophila na Bacia Amazônica como tratando-se realmente de $B$. occi. dentalis. Paraense (1981), ao dar a distribui. ção geográfica de $B$. occidentalis confirma sua presença nos Estados do Acie e Mato Grossc e provaveimente também no Amazonas, ao levar-se em conta observações realizadas com base em conchas provenientes de Tefé.

Paraense \& Corrêa (1982) constataram a não suscetibilidade de $B$. occidentalis de Mato Grosso, Mato Grosso do Sul, Paraná e São Paulo à infecção por S. mansoni de São José dos Campos.

No presente trabalho, procuramos testar a suscetibilidade de $B$. occidentalis de Sena Madureira (Acre) e Cuiabá (Mato Grosso) à infecçâo por S. mansoni de São José dos Cam. pos (São Paulo) e Paulista (Pernambuco).

\section{MAterial E MÉtodos}

Os exemplares de $B$. occidentalis procedentes de Cuiabá foram coletados em um pequeno lago artificial dentro da cidade, onde havia abundância de vegetaçäo aquática constituíaa por Eichornia sp. (Pontederiaceae). Outros exemplaıes da mesma espécie foram obtidos em um brejo às margens da rodovia BR-364, a uns quarenta quilômetros de Cuiabá, em direção à Goiânia.

O procedimento adotado para exame e manutenção em laboratório dos exemplares cole- tados em campo é o mesmo descrito por Coimbra Jr. (1981).

As $B$. occidentalis de Sena Madureira são provenientes da criação do Laboratório de Malacologia, do Departamento de Biologia Animal. da Universidade de, Brasília.

Quanto às B. glabrata usadas como controle, são pertencentes à cepa de Paulista e provenientes do Centro de Pesguisas Aggeu Magalhães, em Recife. Esta cepa foi escolhida para ser usada como controle devido à sua elevada suscetibilidade à infecção por $S$. mansoni.

As cepas de $S$. mansoni utilizadas foram a de Pernambuco, também proveniente do Centro de Pesquisas Aggeu Magalhães, e a de São José dos Campos, obtida no Centro de Pesquisas René Rachou, em Belo Horizonte.

A técnica para obtenção e concentração dos miracídeos é a descrita por Barbosa et al. (1960). Quanto ao procedimento para infecção e exame dos caramujos seguiu-se a técnica descrita em Coimbra Jr. (1981).

\section{Resultados}

Como pode ser visto na Tabela, não se conseguiu a infecção de $B$. occidentalis de Cuiabá (MT) e Sena Madureira (AC), com as cepas de São José dos Campos (SP) e Paulista (PE). Já os B. glabrata de Paulista (PE), usados como controle, se infectaram em $85,7 \%$ com a cepa pernambucana de S. mansoni e em $75,0 \%$ com a cepa de São José dos Campos.

TABELA - Índices de infecção de B. occidentalis do Acre e Mato Grosso pelas cepas de S. mansoni de São José dos Campos e de Paulista, 1982.

$\begin{array}{cccc}\text { Espécies de caramujos } & \text { Cepas de } & \text { Caramujos xepostos } & \text { Caramujos examı- } \\ \text { e origem } & \text { S. mansoni } & \text { à infecçäo (total) } & \text { nados (vivos) }\end{array}$

$\begin{array}{ccccc}\text { B. occidentalis } & \mathrm{PE} & 20 & 15 & 0 \\ (\mathrm{AC}) & \mathrm{SP} & 45 & 35 & 0 \\ \text { B. occidentalis } & \mathrm{PE} & 60 & 52 & 0 \\ (\mathrm{MT}) & \mathrm{SP} & 60 & 49 & 0 \\ \text { B. glabrăta(PE) } & \mathrm{PE} & 20 & 14 & 12(85,7 \%) \\ \text { (controle) } & \mathrm{SP} & 20 & 12 & 09(75,0 \%)\end{array}$




\section{Discussão}

Os dados contidos no presente trabalho vêm confirmar em parte os resultados obtidos por Paraense \& Corrêa (1982) que também não obtiveram a infecção de $B$. occidentalis proveniente das localidades matogrossenses de Cáceres, Pontes e Lacerda e Cuiabá, com a cepa de São josé dos Campos (SJ2) de $S$. mansoni. Por outro lado, os B. tenagophila de Joinville e Taubaté usados pelo autor como controle, se infectaram em $17,9 \%$ e $14,8 \%$. respectivamente.

O grande fluxo migratório direcionado à Amazônia, em especial o Norte de Mato Grosso, Rondônia e Acre, tem levado para essa região grande número de coionos, muitos dos quais portadores de esquistossomose. Nos projetos de colonização, instalados pelo INCRA, ao longo da BR-364 ou nas vilas e cidades localizadas às margens da mesma estrada, c que crescem em rítmo acelerado, verifi. ca-se uma característica marcante - a total ausência de infra-estrutura sanitária. Não há sistema de distribuição de água pelo município, nem de coleta e tratamento de esgotos. Cada família abre o seu próprio poço e fossa, ou entãu serve-se diretamente do rio.

Nessa situação, a prevalência de enteroinfecçōes, hepatite e parasitoses intestinais é bastante elevada e, no que se refere à epidemioiogia da esquistossomose, é preenchido plenamente um dos requisitos para que se dê a transmissão da doença, isto é, uma população de baixo nivel sócio-ecotiômico, vivendo em condições de promiscuidade e insalubridade.

Quanto aos outros requisitos, os de ordem ambiental e biológica, temos uma grande área entrecortada por rios e igarapés, assim como numerosos lagos, com abuntiante vegetação aquática. No entanto, parece haver nesses ambientes límnicos um fator limitante para o desenvolvimento de populações de planorbídeos $-\mathrm{o} \mathrm{pH}$ da água.

Sioli (1967) classifica os rios da Bacia Amazônıca em três tipos e dá seus valores médios „de $\mathrm{pH}$ : a) rios de águas "brancas" (Amazonas, rio Madeira, rio Branco $-\mathrm{pH}$ $6,2-7,2)$ : rios de água clara ou transparente (rios Tapajós e Xingu - pH 4,5-7,8) e, rios do águas "pretas" (rios Negro e Cururu $-\mathrm{pH}$ $3,8-4,9)$. Observa ainda que esses tipos de rios dependem de alguns fatores predominantes em suas cabeceiras, tais como relevo, clima e cobertura vegetal. Segundo o referido autor, um mesmo rio pode ser alimentado por afluentes cujas águas sejam classificadas em outres categorias, ou mesmo, podem mudar suas características periódica ou ocasionalmente.

A construção de represas com o fim de obtenção de energia hidroelétrica, como a represa de Samuel, em construção no rio Jamari, próximo a Porto Velho, pode vir a modificar as condições ecológicas dos ambientes aquáticos e promover sua eutrofização, o que poderia ocasionar uma elevação em seu pH. Além disso, Goodland \& Irwin (1975) advertem para o fato de que os colonos estariam sendo incentivados a colocarem calcário $€$ fertilizantes em suas plantações sem a devida orientação técnica - as chuvas pesadas logo carreariam es. sas substâncias para os poços criados pelas rodovias $e$ as váletas de drenagem, acelerando a eutrofização $\in$ elevando seu $\mathrm{pH}$.

A iciéia de que a região Norte caracterizar. se-ia por uma escassez de moluscos e a ausência quase completa de planorbídeos em sua fauna, compartilhada por diversos autores (Pessoa \& Vianna Martins, 1977), parece não corresponder à realidade, e, a medida em que novas pesquisas vão se desenvolvendo. novos criadouros vão sendo observados e até mesmo, novas espécies descritas.

Também com respeito ao $\mathrm{pH}$ das águas, sabe-se que esse não é o único fator limitante para o desenvolvimento de pcpulações desses moluscos e talvez nem mesmc o mais importante. Meilo \& Barbosa (1969), demonstraram a presença de $B$. glabrata e $B$. straminea em criacouros no Estado de Sergipe onde o pH variava entre 4,5 a 8,0 . Portanto, esses moluscos podem viver em larga faixa iônica.

Em virtude da aceleração do processo de ocupação da Amazônia verificado principalmenle a partir da década de 70 , e consistindo basicamente na implantação de projetos de colonizeção ao longo de rodovias recém abertas que são ocupadas por colonos nordestinos ou 
sulistas, muitos dos quais provenientes de áreas endêmicas, torna-se imperativo o conhecimento da fauna malacológica regional com vistes a determinar seu papel na epidemiologia da esquistossomose na região.

Com respeito à suscetibilidade de $B$. amazonica e B. occidentalis à infecção por S. mansoni, sabemos que a primeira demonstrou ser boa transmissora do parasita, pelo menos em concições de laboratório, pois até o momento não é conhecido nenhum foco de esquistossomose onde essa espécie possa estar implicada como transmissora. Referente a B. occidentalis, o insucesso nas tentativas de infecção pelas cepas de $S$. mansonı de Sào José dos Campos e Paulista, não nos permite concluir pela impcssibilidade dessa espécie de molusco vir a transmitir a doença na região. Para isso, outras cepas de $S$. mansoni devem ser testadas, e, mesmo assim, não podemos nos esquecer da possibilidade de adaptação de cepas de $S$. mansont às cepas locais de B. occidentalis, comc observaram Paraense \& Corrêa (1963) com B. tenagophila.

A existência de B. glabrata merece ser destacacia, pois, trata-se da mais importante espé. cie transmissora de $S$. mansoni nas Américas. Sua occrrência quase sempre está associada a focos bem estabelecidos da doença. A presença dessa espécie no litoral paraense, em Quatipuru, e o fato de já ter sido encontrada. naturalmente infectada na área, nos leva a crer que essa faixa litorânea seja uma região de eleição para o estabelecimento de uma extensa area de transmissão da doença, tal como no Estado vizinho, o Maranhăo. Nesse Estado, a esciuistossomose tem sido assinalada em vários municípios, como Cururupu, Turiaçu, São Vicente Ferrer e São Bento, estando todos esses focos associados a B. giabrata.

Outro estudo importante a ser desenvolvido é sobre as condições ecológicas dos diversos tipos de ambientes límnicos e sua relação com as populações de planorbídeos, de modo a demonstrar efetivamente quais são os fatores ciue influem na dinâmica de suas populaçöes e quais as conseqüências dos desmatamentos ao"longo dos rios assim como da construção de represas e drenagens sobre a biologia desses moluscos.

\section{Agradecimentos}

Ao prof. Frederico Simões Barbosa, da Universidade Federal de São Carlos, pela orientação e revisão dos originais: ao Dr. Naftale Katz, do Centro de Pesquisas René Rachou em Belo Horizonte, pelo fornecimento da cepa de S. mansoni de São José dos Campos; à bióloga Cláudia Alves de Magalhães do Laboratório de Malacologia, do Departamento de Biologia Animal, da Universidade de Brasília, pela cortesia de ceder-nos a cepa de $B$. occidentalis de Sena Madureira.

\section{SUMMARY}

This paper reports the studies on the susceptibility of Biomphalaria occidentalis from Sena Madureira (Acre) and Cuiabá (Mato Grosso) to infection by Schistosoma mansoni from São José dos Campos (São Paulo) and Paulista (Pernambuco). The attempts of infection where negative. The authors also comments about the geographical distribution of planorbid snails in the Amazon basin and the authochtonous foci known in the region. The possible role of $\mathbf{B}$. occidentalis in the transmission of schistosomiasis is discussed.

\section{REFERENCIAS BIBLIOGRÁFICAS}

BARBOSA, F.S.

1968 - A note on Biomphalaria straminea (Dunker, 1848) from Manaus, State of Amazonas, Brazil. Rev. Soc. Brasil. Med. Trop., 2 (2): 77-78.

BARBOSA, F.S. et al.

1960 - Manual de Malacologia Médica. Fundaçâo Gonçalo Muniz. Salvador, Bahia.

CNPq

1978 - Epidemiologia e Controle da Esquistossomose e o Nordeste Semi-Árido. Frederico S. Barbosa (coord.). Relatório do Grupo de Trabalho reunido em Recife de 24 a 28 de abril de 1978 .

COIMBRA Jr., C.E.A.

1981 - Suscetibilidade à infecção pelo Schistosoma mansoni, de Biomphalaria glabrata e Biomphalaria tenagophila do Distrito Federal, Brasil. Rev. Saúde Públ., S. Paulo, 15: 485-489.

CORREA, L.R. \& PARAENSE, W.L.

1971 - Susceptibility of Biomphalaria amazonica to infection with two strains of Schistosoma mansoni. Rev. Inst. Med. Trop. São Paulo, 13 (6): $387-390$. 
FRAIHA, $\mathrm{H}$

1977 - Panorama Atual das Parasitoses na Amazô. nia. Rev. Fund. SESP, 22 (1): 7-20.

FRAIHA, H. \& MORAES, M.A.P. de

1976 - Esquistossomose. In: Pinheiro, F.P. Patologia Tropical na Amazônia: Recentes Aquisições. In: Veronesi, R. (ed.) - Doenças infecciosas e Parasitárias, 6." ed., Ed. Guanabara Koogan, Rio de Janeiro, pp. 1058-1059.

1979 - Esquistossomose. In: Saúde na Amazônia. (F. de P. Pinheiro, coord.). Associação Nacional de Programação Econômica e Social - ANPES, São Paulo.

GALVĀO, S.

1968 - Esquistossomose em Belém, do Pará. Rev. Bras. Malariol. D. Trop., 20 (3/4): 215223.

GOODLAND, R. \& IRWIN, H.

1975 - A Selva Amazônica: Do Inferno Verde ao Deserto Vermelho? Col. Reconquista do Brasil, vol. 30. EDUSP/Livraria Itatiaia Ltda., São Paulo.

MACHADO, W.G. \& MARTINS, C.

1951 - Um Foco Autóctone de Schistossomose no Pará (Nota Prévia) O Hospital, 39: 289-290.

MELLO, D.A. \& BARBOSA, F.S.

1969 - Estudos sobre os Planorbídeos Transmissores da Esquistossomose Mansônica no Estado de Sergipe. Gaz, méd. Bahia, 69 (3): 123-136.

MELLO, M.J.P. \& GUEIROS, Z.M.

1959 - Novo Foco de Esquistossomose Mansônica na Amazônia (Foco de Quatipuru, Município de Capanema, Estado do Pará). TrabaIho apresentado à 1.: Jornada Médica $\mathrm{Pa}$ raense, Capanema, Pará.
PARAENSE, W.L.

1966 - Biomphalaria amazonica and B. cousini, two new species of Neotropical Planorbid Mollusc. Rev. Brasil. Biol., 26 (2): 115-126.

1981 - Biomphalaria occidentalis sp. n. from South America (Mollusca Basommatophora Pulmonata). Mem. Inst. Oswaldo Cruz, 76 (2): 199-211.

PARAENSE, W.L. \& CORREA, L.R.

1963 - Suscpetibility of Australorbis tenapophilus to infecton with Schistosoma mansoni. Rev. Inst. Med. Trop. Săo Paulo, 5: 23-29.

1982 - Unsusceptibility of Biomphalaria occidenta. lis to infection with a strain of Schistoso. ma mansoni. Mem. inst. Osvaldo Cruz, 77 (1): $55-58$.

PESSOA, S.B. \& VIANNA-MARTINS, A.

1977 - Parasitologia Médica. 10. ed. Editora Guanabara Koogan, Rio de Janeiro.

RUIZ, R.A.

1974/75 - Infestação experimental de exemplares de Biomphalaria straminea capturados na regiāo da Transamazônica. Rev. Bras. Malariol. D. Trop., 26-27: 105-108.

SIOLI, H.

1953 - Limnologische Untersuchungen und Betrachtungen zur erstmaligen Entdeckung endemischer Schistosomiasis (Sch. mansoni) im Amazonasgebiet. Arch. Hydrobiol., 48 (1): $1-23$.

1967 - Studies in Amazonian Waters. In: Atas do Simpósio sobre a Biota Amazônica 3 (Limnologia): 9-50, Rio de Janeiro.

(Aceito para publicaçăo em 27/09/82) 